\title{
The Role and Place of the Podcast in the Digital Market
}

\author{
Assist. Prof. PhD Boycho Boychev \\ St. Cyril and St. Methodius University of Veliko Turnovo, Veliko Turnovo, Bulgaria \\ b.boychev@ts.uni-vt.bg
}

\begin{abstract}
In the last few years the podcast has started to enter the Bulgarian media market. It is a relatively new and little known on demand media product in Bulgaria. Abroad, podcasts have gained popularity with advertisers as an effective way to reach their target audience. The reason for this popularity is the niche content delivered to the target audience. Advertisers believe that these audiences are tight-lipped, which allows them to better understand the branding message and therefore have greater impact on the consumer. The purpose of the development is to acquaint the reader with the available podcasts in Bulgaria and the opportunities offered for advertising in them.
\end{abstract}

Keywords: Podcast, Marketing, Advertising, Podcast advertising, Digital market

JEL Code:M31, M37; doi:10.36997/IJUSV-ESS/2019.8.2.94

\section{Въведение}

През последните няколко години на българския медиен пазар почна да навлиза nодкастъm. Това е относително нов и слабо познат медиен продукт от тип „при поискване“ (on demand) в България. В чужбина подкастите са придобили популярност сред рекламодателите като ефективен метод за достигане до тяхната целева аудитория. Причината за тази популярност е нишевото съдържание, доставено на целевата аудитория. Рекламодателите считат, че тези аудитории са тясно насочени, което дава възможност за подоброто възприемане на рекламното послание на търговските марки и следователно поголямо въздействие върху потребителя.

\section{1. Сыщност на подкастинга}

За първи път подкастинга бива споменат в статията на Хамерсли ${ }^{1}$ като понятие. По сериозното му навлизане започва през 2005 г., когато Аpple добавя официална поддръжка на подкастите в iTunes, с което се налага като новост и затвърждава новото понятие. Първоначалната идея е била радиопредаване да се запише и качи в Интернет като слушателите да свалят с цел да изслушат предаването в удобно за тях време. С времето се появяват специално записани файлове с цел споделяне в интернет без някога да са били изльчвани по радио станиция. „Подкастта е дигитален аудио файл на радиопредаване или независимо предаване, който е наличен в интернет за сваляне““2. Той все по-често се използва като платформа за рекламни послания ${ }^{3}$. Маркетолозите и рекламодателите могат да предадат рекламно съобщение или да напредставят търговската марка преди, по време и/или след представянето на съдържанието на подкаста.

Според проучване от 2018 г. на Acast 23\% от жителите на Великобритания слушат подкасти, а 76\% са повлияни от рекламата да заплатят за рекламирания продукт или услуга, за която са чули в шоуто ${ }^{4}$.

\footnotetext{
${ }^{1}$ Hammersley, Ben. Audible revolution. 12.2.2004, https://www.theguardian.com/media/2004/feb/12/broadcasting.digitalmedia

2 Ritter, E. A., \& Cho, C. (2009). Effects of Ad Placement and Type on Consumer Responses to Podcast Ads. CyberPsychology \& Behavior,12(5), 533-537. doi:10.1089/cpb.2009.0074

${ }^{3}$ McGowan, M. K. (2010). The Unexplored New Medium: Recent Trends in Podcast Advertising. The Elon Journal of Undergraduate Research in Communications,1(2), 97- 111.

4 Stewart, Rebecca. 76\% of UK listeners have acted on a podcast ad according to Acast, 2.4.2018, https://www.thedrum.com/news/2018/04/02/76-uk-listeners-have-acted-podcast-ad-according-acast
} 
Подобни проучвания се извършват и в САЩ. Една от изследователските групи е Edison Research and Triton Digital. Тя провежда изследвания от 2006 години до сега. Последното проучването на групата „The Infinite Dial $2019^{“ 5}$ е публикувано в началото на март 2019 г. Изследването е проведено сред хора от 12 години до 65. В доклада са изнесени данни от проучването на подкастинга от 2006 г. до 2019 г. За разглеждания период прави впечатление, че единствено през 2013 г. има лек спад в слушателите на този тип файлове (виж фиг. 1), който бива компенсиран и от представените данни можем да заключим, че има трайна тенденция към увеличаване на слушателите. Според друга изследователска група WARC, 22\% населението на САЩ - около 62 млн. души, слушат подкаст ${ }^{6}$ и спрямо тяхното излседване също се увеличава броя на слушателите.

Тази тенденция предоставя разрастващ се рекламен канал, чрез който може да тьрговските марки да достигнат до свойте потенциални клиенти.

\section{Подкастинг слушатели в проценти}

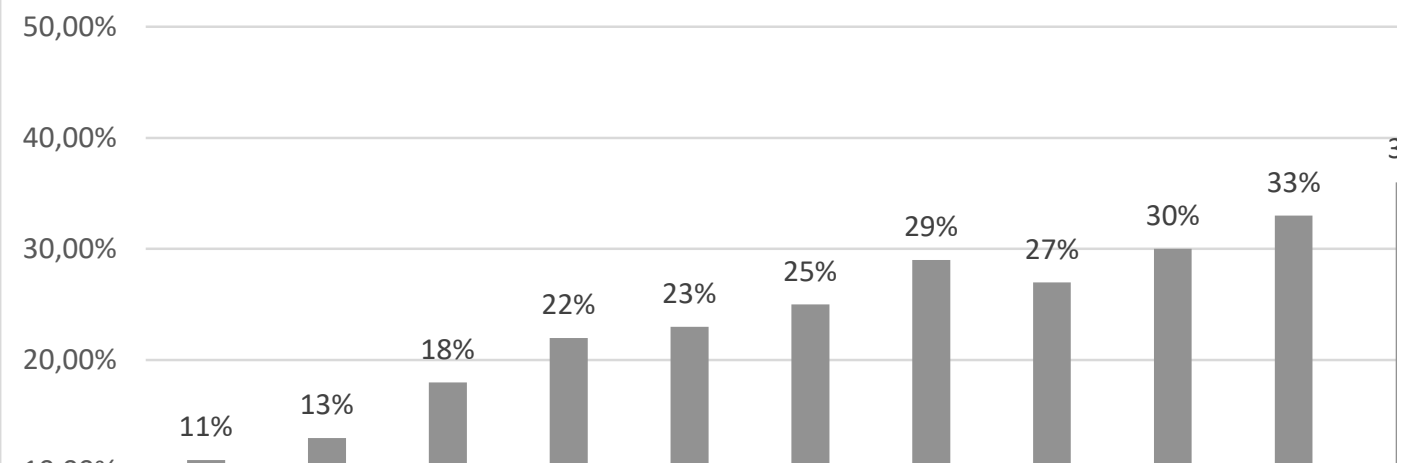

Фигура. 1 Подкастинг слушатели в САЩ в периода 2006-2019

B iTunes ${ }^{7}$ - платформа на Apple, има над 550000 подкаста с над 18,5 млн. записа като в световен мащаб има около 660000 подкаста и този брой продължава да нараства.

Предпоставка за това е, че за самото създаване на подкаст не изисква сериозни инвестиции. Необходими са микрофон, слушалки, компютьр свързан към интернет и малка сума пари за онлайн услуги. При създаването на епизод следва да се спазват някой препоръки с цел да се запази качеството на записа:

$>$ слушалките трябва да упльтняват добре за да не се връща звук от тях в микрофона;

$>$ трябва да се съблюдава да няма странични шумове;

$>$ записа трябва да се извършва в максимално тиха стая без отворени врати или прозорци;

$>$ трябва да се избягва по време на записа да се говори близко и срещу стена поради създаване на ехо, както и стаите с високи тавани поради същата причина;

$>$ най-оптималното място за провеждане на запис е в средата на стаята;

$>$ микрофона трябва да е поставен по подходящ начин, които няма да се влияе от движения по масата;

\footnotetext{
5 Доклада е публикуван на 6.3.2019 https://www.edisonresearch.com/infinite-dial-2019/

${ }^{6}$ WARC, Global Ad Trends - Podcasts, April 2019. http://eu-lon09.marketo.com/lp/785-GVO-306/April_Global-AdTrends-2019.html

${ }^{7}$ https://www.apple.com/itunes/podcasts/
} 
$>$ при запис на двама и повече хора те трябва да стоя на разстояние един от друг поне 2 метра за да не се получи микрофония.

За маркетолозите важен момент, спрямо договора за реклама, е правилното оформление на съдържанието, чрез което ще се представи бранда по време на епизода, когато това е заложено да бъде част от основното съдържание.

След преключване на записа е необходима допълнителна обработка на епизода. През този етап също могат да се добавят или коригират рекламните послания. Тази обработка се осъществява чрез софтуер за редакция. В този процес се обработва силата на звука, което е от изключително голямо значение за възприемането, както на самото съдържание така и на рекламното послание. Известно е, че интонацията и силата на звука са от съществено значение за начина, по който ще бъде възприемо съдържанието и в частност самата реклама. Благодарение на софтуера могат да се премахнат нежелани моменти, да се корикират тихите или силни части от записа, да се премахнат „пукания“ и други несъвършенства. След финализирането на обработката е желателно рекламодателите да чуят епизода за да са сигурно за качеството, както на самото съдържание така и за доброто представяне на рекламното послание на търговската марка. След финалното одобрение последва компресиране на файла с цел намаляване на неговия размер преди качване в Инернет. За да бъде класифициран в правилната категория в агрегаторите епизода е необходимо да се въведат мета данни във фийда като автор, заглавие, подзаглавие, описание, език, категория, подкатегория и други. След създаването на файла, обработката, компресирането и създаването на фийда се публикува. Най-големите мрежи за публикуване на подкасти са Spotify, Apple iTunes Store и Google Podcasts. Благодарение на тези мрежи рекламата може да достигне до огромна аудитория. Те позволяват да се извежда статистика по пол, възраст, колко души са изслушали до край епизода и друга значима информация за рекламодателите.

Поради тези причини се прогнозира увеличаване до 4,5\% от глобалните разходи за аудио реклама до 2022 г. да биват за реклами в подкаст спрямо 1,9\% през 2018 г. ${ }^{8}$

\section{2. Подкасти в България}

За България подкаста е нещо ново. В повечето български подкасти няма реклама като цяло, а се разчита на лични средства и/или на дарения за създаването и поддържането им. Това създава добра възможност за българските рекламодатели да достигнат до добре подбрана и таргетирана група последователи на дадения подкаст. Създаване на качествено съдържание с включена реклама в подкаста още в процес на формиране на българския пазар. Все още българските маркетингови специалисти не са привлечени от този тип медия, но според нас подкаста ще оказва за напред значително влияние върху маркетинговите стратегии на бизнес организациите (и не само), както в световен мащаб така и в България. За нарастващото значение на подкастите в световен мащаб ни навежда на мисълта и направената инвестицията от страна на Spotify на стойност 500 млн. долара в закупуването на мрежата от подкасти Gimlet. ${ }^{9}$

За сравнително краткото време в България се появиха подкасти на различна тематика - от кино до политика. Някой от тях редовно биват обогатявани с нови епизоди (виж таб. 1), а други биват изоставяни и не се развиват - не са публикувани нови епизоди повече от година ${ }^{10}$ (виж. таб. 2).

\footnotetext{
${ }^{8}$ WARC, Global Ad Trends - Podcasts, April 2019. http://eu-lon09.marketo.com/lp/785-GVO-306/April_Global-AdTrends-2019.html

${ }^{9}$ Chmielewski Dawn. It's Official: Spotify Buys Gimlet Media, Plans To Spend Up To \$500 Million This Year on Acquisitions. 6.2.2019. https://www.forbes.com/sites/dawnchmielewski/2019/02/06/its-official-spotify-buys-gimletmedia-plans-to-spend-up-to-500-million-this-year-on-acquisitions/

${ }^{10}$ Към момента на писане на разработката 24.7.2019 г.
} 
Таблица 1. Списък на активни български подкасти

\begin{tabular}{|c|c|c|}
\hline № & Подкаст & Описание $^{11}$ и адрес \\
\hline 1 & $\begin{array}{l}\text { Свръхчовекът с } \\
\text { Георги Ненов }\end{array}$ & $\begin{array}{l}\text { Свръхчовекът е българският подкаст, насочен към вярата в себе си и } \\
\text { многобройните възможности, които ни заобикалят. Разказвайки } \\
\text { вдъхновяващи истории на хора, които живеят живота на мечтите си, } \\
\text { Георги Ненов цели да мотивира своите слушатели да вървят по пьтя си с } \\
\text { увереност в собствените си способности и така да сьтворят едно по- } \\
\text { добро бъдеще. https://soundcloud.com/thesuperhumanpodcast/tracks }\end{array}$ \\
\hline 2 & Непримиримите & $\begin{array}{l}\text { Непримиримите е български подкаст за разговори с вдъхновяващи и } \\
\text { борбени личности, сбъдващи мечтите си! https://soundcloud.com/ } \\
\text { neprimirimite }\end{array}$ \\
\hline 3 & ТехБалон & Български подкаст за технологиите от света. https://www.techballoon.net/ \\
\hline 4 & Сонар Каст & $\begin{array}{l}\text { Интервю подкаст на български за бизнес, технологии и култура. } \\
\text { https://sonar.libsyn.com/ }\end{array}$ \\
\hline 5 & $\begin{array}{l}\text { Камък, ножица, } \\
\text { хартия }\end{array}$ & $\begin{array}{lllllll}\text { Седмичният подкаст за култура, ново } & \text { време } & \text { и } & \text { още } & \text { нещо. } \\
\text { https://soundcloud.com/thekanoha }\end{array}$ \\
\hline 6 & $\begin{array}{l}\text { Тихо, филмът } \\
\text { започва by } \\
\text { WebcafePro }\end{array}$ & $\begin{array}{l}\text { Подкаст за хората от уеб сайтовете в мрежата на webcafe.bg. } \\
\text { https://soundcloud.com/webcafebg }\end{array}$ \\
\hline 7 & $\begin{array}{l}\text { The Comedy } \\
\text { Club Channel }\end{array}$ & $\begin{array}{l}\text { Подкаст на Комеди Клуб София с най-добрите стендъп комедианти в } \\
\text { България и приятели има и YouTube канал, където се качват и видео от } \\
\text { падкастите. https://soundcloud.com/user-243077722 }\end{array}$ \\
\hline 8 & Nerds2Nerds & $\begin{array}{l}\text { Nerds2Nerds е подкаст за информационни технологии, програмиране и } \\
\text { наука. https://www.nerds2nerds.com/ }\end{array}$ \\
\hline 9 & $\begin{array}{l}\text { Hill Season } \\
\text { Podcast }\end{array}$ & $\begin{array}{l}\text { Този подкаст е фокусиран върху велосипедистите. Епизодите са гости, } \\
\text { които разказват за интересни състезания от България и чужбина. } \\
\text { http://hillseason.com/ }\end{array}$ \\
\hline 10 & Ratio Podcast & $\begin{array}{l}\text { Подкастьт е за “общо любопитни хора". Тук ще чуете по-неформални, } \\
\text { често по-неподготвени разговори, свързани и вдъхновени от наука - } \\
\text { всичко това през призмата на абсолютния лаик (в ролята - Любо) и } \\
\text { интересни събеседници (практически, всички останали участници). } \\
\text { https://soundcloud.com/ratiobg }\end{array}$ \\
\hline 11 & $\begin{array}{l}\text { Създателите - } \\
\text { дигиталните } \\
\text { оптимисти на } \\
\text { България }\end{array}$ & $\begin{array}{l}\text { В подкаста се говори в различни формати за дигиталното общество в } \\
\text { България, за хората, които ежедневно инвестират време, идеи, пари и } \\
\text { развиват този бизнес у нас. https://thecreators.bg/podcast/ }\end{array}$ \\
\hline 12 & TopkastBg & $\begin{array}{l}\text { Спортен футболен подкаст, в който се коментират актуалните футболни } \\
\text { първенства и турнири - Шампионската лига, Премиър лийг, Примера } \\
\text { дивисион, Бундеслига, Серия А, Лига 1, както и българското футболно } \\
\text { първенство. https://anchor.fm/topkast-bg }\end{array}$ \\
\hline 13 & GYMonBOOKS & Фитнес подкаст шоу. https://soundcloud.com/gymonbooks \\
\hline 14 & Beyond Numbers & $\begin{array}{l}\text { B Beyond Numbers ще обсьждат какво стои зад сьздаването и развитието } \\
\text { на един бизнес. Подкаст за предприемаческата дейност. } \\
\text { https://beyondnumbersshow.com/l }\end{array}$ \\
\hline 15 & $\begin{array}{l}\text { SBS на } \\
\text { Български }\end{array}$ & $\begin{array}{l}\text { Интервюта и кратки политически новини от българското } \\
\text { представителство на международната мултимедийна мрежа SBS, която е } \\
\text { основана в Австралия. https://www.sbs.com.au/yourlanguage/bulgarian/en/ } \\
\text { podcastcollection/sbs-bulgarian }\end{array}$ \\
\hline 16 & Тоест & $\begin{array}{l}\text { Интернет медия, която е финансирана единствено от слушателите си. } \\
\text { Бавна, обмислена и честна журналистика. Без реклами и платени } \\
\text { репортажи. Без подвеждащи заглавия и сензации. https://toest.bg/ }\end{array}$ \\
\hline
\end{tabular}

${ }^{11}$ Описанито за подкаста е взето от страницата на съответния подкаст. 
IZVESTIA JOURNAL OF THE UNION OF SCIENTISTS - VARNA

\begin{tabular}{|c|c|c|}
\hline № & Подкаст & Описание $^{11}$ и адрес \\
\hline 17 & $\begin{array}{c}\text { Несвъртък с } \\
\text { Пламен Сивов }\end{array}$ & $\begin{array}{l}\text { Говори се за култура, религия, музика и се опитва да погледне отвъд } \\
\text { видимостите и събитията. Подкастът включва тв- и радиоинтервюта, } \\
\text { както и собствени епизоди. https://anchor.fm/plamen-sivov }\end{array}$ \\
\hline 18 & Сол на Живота & $\begin{array}{l}\text { В този подкаст се разговаря за срещата на вътрешно-християнския живот } \\
\text { с предизвикателствата на динамичния и забързан ден. Разговори се водят } \\
\text { със свещеници, деатели, доброволци и обикновени миряни. Темите, } \\
\text { които се засягат са такива, които живо вълнуват нашето ежедневие на } \\
\text { Православни християни. https://www.buzzsprout.com/262762 }\end{array}$ \\
\hline 19 & --force push & $\begin{array}{l}\text { Разговори със софтуерни разработчици от екипа на ReceiptBank. Говорят } \\
\text { за нещата, които ca научили, учат или ще научат някога. } \\
\text { https://forcepush.simplecast.com/ }\end{array}$ \\
\hline 20 & Да, България! & $\begin{array}{l}\text { Официален подкаст на политическа партия „Движение Да, България“, в } \\
\text { който се обсъждат теми свързани с миналото, настоящето и бъдещето на } \\
\text { България. https://www.dabulgaria.bg/podcast/ }\end{array}$ \\
\hline 21 & Превод в ефир & $\begin{array}{l}\text { Седмичен подкаст на Свободна Европа с Полина Паунова. От началото } \\
\text { на } 2019 \text { г. Свободна Европа е възстановена като дигитална платформа за } \\
\text { предоставяне на мултимедийно съдържание на български език. Засягат се } \\
\text { предимно политически и журналистически теми. Има още два свързани } \\
\text { подкаста от Полина Паунова - Говори Полина и Мило Дневниче. } \\
\text { https://www.svobodnaevropa.bg/a/29918946.html }\end{array}$ \\
\hline
\end{tabular}

Таблица 2. Списък на неразвиващи се подкасти в България.

\begin{tabular}{|c|c|c|}
\hline № & Подкаст & Описание и адрес \\
\hline 1 & „Градски детектив“ & $\begin{array}{l}\text { „Градски детектив“ е подкаст за градски легенди и } \\
\text { любопитни моменти от архитектурната и културна история } \\
\text { на градовете. Автори ca Ана Благова, Яна Пункина и } \\
\text { Радослав Чичев. http://www.detectivepodcast.com/ }\end{array}$ \\
\hline 2 & freedomonline.bg & $\begin{array}{l}\text { Подкастът на freedomonline.bg е допълнения към блога им, } \\
\text { където публикуват материали свързани със сигурност, } \\
\text { кибер уязвимост и атаки. https://soundcloud.com/ } \\
\text { freedomonlinebg }\end{array}$ \\
\hline 3 & WakeUp and StartUp & $\begin{array}{l}\text { Подкаст с гости предприемачи, които споделят своя опит } \\
\text { към успеха. https://soundcloud.com/wakeupandstartup }\end{array}$ \\
\hline 4 & Предприемачите & $\begin{array}{l}\text { Подкаст обмислян да обхваща широк крьг от теми. } \\
\text { http://predpriemachite.com/ }\end{array}$ \\
\hline 5 & София сутрин & https://soundcloud.com/sofiasutrin / \\
\hline 6 & ФизиоБГ & $\begin{array}{l}\text { Идеята е била да се представят неща свързани с } \\
\text { физиотерапията. https://soundcloud.com/rehabilitation-plovdiv }\end{array}$ \\
\hline 7 & Birecast & $\begin{array}{l}\text { Подкаст за кино, сериали, комикси, кеч и музика. } \\
\text { https://bireto.blogspot.com/p/blog-page_13.html }\end{array}$ \\
\hline 8 & $\begin{array}{l}\text { Gamers' Voiceshop } \\
\text { (GVS) }\end{array}$ & $\begin{array}{l}\text { Подкаст за всичко, свързано с гейминга като хоби, } \\
\text { развлечение и дори професия. http://gamersvoiceshop.com/ } \\
\text { gvs-episodes/ }\end{array}$ \\
\hline
\end{tabular}

Освен представените в таблица 1 редовно обновявани подкасти има и една мрежа от подкасти, която се развива успешно в България. Първия подкаст пуснат от тази мрежа е „Говори ѝнтернет“12. Старта му е през 2017 г. В „Говори ѝнтернет“ тематиките са най-

\footnotetext{
${ }^{12}$ Адрес на подкаста https://govori-internet.com/
} 
разнообразни. На 23.07.2018 г. с помощта на създателите на „Говори иेнтернет“ тръгва подкаста „Транзйстор“13 свързан с потеребителските технологии, а в края на същата година 30. 12.2018 г. бива пуснат пилотния епизод на „Дроб и чили“14, който е свързан с храната и храненето като цяло. Към мрежата през март 2019 г се добавя и „Експлейнърът на ГЙ“15. Всички епизоди на цялата мрежа могат да се намерят на този адрес: https://soundcloud.com/govori-internet.

Повечето подкасти в България се финансират изцяло чрез лични средства и/или чрез дарения. По същия начин започва и „Говори иेнтернет“ - чрез лични инвестиции и чрез дарения от над 100 души в платформата Patreon. От скоро „Говори иेнтернет“ се опитва да комерсиализира своят медиен канал. Макар и да са в самото начало на това свое начинание, те вече са успели да добавят по 2-3 рекламни блока с продължителност от по 1 минута в епизод с времетраене от 2 часа. Това показва, че макар и бавно рекламодателите в България почват да виждат потенциал в този тип медия.

\section{Заключение}

Все по дълбокото навлизане на технологиите в ежедневието и променящите се нужди на потребителите изменят предпочитанията им на медии. От цитираните проучвания ставя ясно, че подкаста е все по-разрастващ се рекламен канал, чрез който търговските марки се опитват да спечелят вниманието на слушателите. За разлика от уеб рекламата те се четат от авторите на съдържанието и слушателите имат нагласата да ги чуят с цялото си внимание. Това дава причина да смятаме, че има значима преспектива за развитие на реклама в подкаста. Важна разлика в сравнение с традицинните медии е че тук няма ограничения в рекламния блок, което дава голяма свобода на на действие от страна на рекламодателите, а това е значимо предимство пред традицинните медии.

\section{References}

1. Chmielewski Dawn. It's Official: Spotify Buys Gimlet Media, Plans To Spend Up To $\$ 500$ Million This Year on Acquisitions. 6.2.2019. https://www.forbes.com/sites/dawnchmielewski/ 2019/02/06/its-official-spotify-buys-gimlet-media-plans-to-spend-up-to-500-million-this-yearon-acquisitions/

2. Edison Research and Triton Digital. The Infinite Dial 2019. 6.3. 2019 https://www.edisonresearch.com/infinite-dial-2019/

3. Hammersley, Ben. Audible revolution. 12.2.2004 <https://www.theguardian.com/media/ 2004/feb/12/broadcasting.digitalmedia>

4. McGowan, M. K. (2010). The Unexplored New Medium: Recent Trends in Podcast Advertising. The Elon Journal of Undergraduate Research in Communications, 1(2), 97- 111.

5. Ritter, E. A., \& Cho, C. (2009). Effects of Ad Placement and Type on Consumer Responses to Podcast Ads. CyberPsychology \& Behavior,12(5), 533-537. doi:10.1089/cpb.2009.0074

6. Stewart, Rebecca. $76 \%$ of UK listeners have acted on a podcast ad according to Acast, 2.4.2018, https://www.thedrum.com/news/2018/04/02/76-uk-listeners-have-acted-podcast-adaccording-acast

7. WARC, Global Ad Trends - Podcasts, April 2019. http://eu-lon09.marketo.com/lp/785-GVO306/April_Global-Ad-Trends-2019.html

\footnotetext{
${ }^{13}$ Адрес на подкаста https://tranzistor.net/

${ }^{14}$ Адрес на подкаста https://drob-chili.com/

${ }^{15}$ Адрес на подкаста https://x.govori-internet.com/
} 